\title{
Dynamic variation of supernatant quality in a dairy shed waste stabilisation pond system
}

\author{
J. Fyfe, M. Sivakumar, D. Hagare and A. Jenkins
}

Sustainable Water and Energy Research Group (SWERG), School of Civil, Mining and Environmental Engineering, Faculty of Engineering, University of Wollongong, Wollongong, Australia

\begin{abstract}
An intensive monitoring program of a standard two-stage dairy shed waste stabilisation pond system was undertaken to determine the incidence and extent of spatial and temporal variation of basic physio-chemical parameters, and to shed light on the longer term dynamic nature of in-pond conditions. The anaerobic-facultative pond system, located in a remote rural area, treats wastewater from the hosing down and hydraulic flushing of the milking parlour and holding yard at the farm dairy shed. A number of multi-parameter water quality field monitoring probes were permanently deployed at various locations within the two ponds to enable continuous measurement of temperature, $\mathrm{pH}$, conductivity and dissolved oxygen. In addition, profiling of the supernatant of both ponds was undertaken at different times of the year to examine vertical variation of the same parameters. Continuous monitoring revealed spatial homogeneity in EC and $\mathrm{pH}$ levels in the upper metre of both ponds. Physio-chemical parameters also appear to change uniformly across the ponds in response to external stimuli such as rainfall. Neither pond, however, exhibits homogeneity down the profile of the supernatant. Seasonal stratification is prevalent in the facultative pond suggesting poor vertical mixing, while the anaerobic pond is notably affected by sludge accumulation. A long-term pattern of rising conductivity in both ponds indicated accumulation of dissolved salt species in the system due to recirculation of reclaimed effluent for hydraulic flushing of the dairy shed. In the facultative pond, diurnal fluctuations in dissolved oxygen, oxidation-reduction potential and turbidity during warmer months of the year closely followed temperature swings. The extensive data collected in this study provides a detailed picture of the physio-chemical dynamics of two-stage stabilisation pond systems treating dairy shed wastewater.
\end{abstract}

\section{INTRODUCTION}

Characterisation and monitoring of supernatant and effluent is a fundamental component of any research on or performance evaluation of waste stabilisation ponds (WSPs) (Pearson et al., 1987). The increasingly widespread adoption of WSPs in the management of municipal, industrial and agricultural waste further entrenches the need for a sound appreciation of their functionality (or otherwise) under different applications. Stabilisation pond monitoring typically involves the analysis of a number or series of intermittently collected grab samples that provides snapshots of information about the wastewater under scrutiny. The data is often used to determine trends in the operation and performance of a pond system and for design and modelling purposes. Alternatively, a pond system may be subject to a brief period of more intense sampling and analysis for the purpose of examining specific phenomena associated with waste stabilisation pond functionality (eg. Craggs et al., 2000; Aneja et al. 2001). Diurnal variation of in-pond conditions has frequently been the subject of such investigations (Kayombo et al., 2002; Sund et al., 2001; Tadesse et al., 2004), which has shed light on the very short term dynamics of pond behaviour. Fewer studies, however, explicitly consider the variation of supernatant or effluent quality on both a prolonged and continuous basis. Long term, high frequency monitoring can not only provide a very detailed picture of pond conditions through high resolution data but can also reduce or eliminate the impact of stochastic variation that can potentially upset interpretation of and the identification of trends in normal low resolution time series data. The aim of this study is to examine the dynamic variation, both temporal and spatial, of basic in-pond supernatant conditions including, temperature, $\mathrm{pH}$, oxidation reduction potential (ORP), electrical conductivity (EC) and dissolved oxygen (DO) within a two-stage dairy shed waste stabilisation pond system.

In relation to characterisation and monitoring of dairy shed waste stabilisation pond supernatant/effluent, a number of studies have involved the intermittent collection and analysis of grab samples for effluent characterisation including those by Hickey et al. (1989), Sweeten and Wolfe (1994), Mason (1996), Sukias et al. (2001) and Bolan et al. (2004). Sukias et al. (2001) 
complemented their grab sample time series data with some profiling and diurnal variation testing of facultative pond supernatant. Sukias et al. (2003) also made brief mention of results from facultative pond profiling and diurnal variation monitoring. This paper describes the specific attempt to examine the underlying supernatant quality conditions that influence the physical, chemical and biological processes within a dairy shed waste stabilisation pond system. Both short term (diurnal) fluctuations and longer term (seasonal and greater) trends are revealed through the ongoing deployment of continuously logged multi-parameter field probes. Spatial variation is investigated through the deployment of several probes at different locations within the ponds, and through extensive profiling of the water column of each pond at different times of the year.

\section{MATERIALS AND METHODS}

\section{Study Site}

The study has been conducted on a 300-head dairy farm located in the Southern Highlands region of NSW, Australia. The herd is milked twice a day in a large modern dairy shed equipped with a rotating platform semi-automated milking system. Wastewater rich in organic material and nutrients is generated from the hosing and hydraulic flushing of the dairy shed and holding yard to remove accumulated manure and urine. The raw wastewater drains first to a trafficable solids trap for removal of coarse particulate matter before it enters an anaerobic pond which is designed primarily for sedimentation and to reduce the high organic loading of the wastewater. The effluent from the anaerobic pond flows to a facultative pond that provides secondary treatment and storage capacity. From the facultative pond the wastewater is reclaimed for the hydraulic flushing (flood wash) of the holding yard and periodically irrigated to land.

\section{Continuous monitoring}

For continuous measurement of temperature, $\mathrm{pH}$ and EC, five self-logging multi-parameter probes (Greenspan CTDP300 Smart Sensor) with solar power support were deployed at several different locations in both ponds. Three were installed in the primary anaerobic pond between 50 to $75 \mathrm{~cm}$ depth, one in the facultative pond (at least $50 \mathrm{~cm}$ depth but variable due to changing supernatant level) and the fifth at the bottom of the flood wash tank that held effluent pumped from the facultative pond. A sixth probe capable of measuring DO as well as the other parameters (Greenspan CS304 Smart Sensor) was deployed in the upper 10-15 cm (epilimnion) of the facultative pond. To compliment the data from the multi-parameter probes in the facultative pond, a Greenspan Mini-analyser (MA) was set up in an enclosed trailer adjacent to the pond to provide laboratory-grade measurement of temperature, $\mathrm{pH}$, oxidation-reduction potential (ORP), conductivity, DO and turbidity by flow injection analysis. Supernatant from the upper 10-15 cm of the facultative pond was supplied to the MA via a submersible diaphragm pump located in the centre of the facultative pond. A schematic diagram of the pond system showing the location of the various probes and the MA is given in Figure 1.

Data was recorded continuously by the probes and the mini-analyser from November 2004 through to July 2006. The probes were programmed to record a reading at least every 30 minutes, and a scan interval of 5 minutes was used to detect and record changes in parameters greater than predetermined trigger values, which were set at $1.0{ }^{\circ} \mathrm{C}, 0.5,250-500 \mu \mathrm{S} / \mathrm{cm}$ and $1.0 \mathrm{mg} / \mathrm{L}$ for temperature, $\mathrm{pH}$, EC and DO, respectively. Initially the MA was programmed to pump and analyse sample every 30 minutes, but on account of the resulting rapid rate of cleansing solutions, the program was modified to sample every 30 minutes during the day and every 3 hours overnight. Due to operational problems such as wayward calibrations and equipment failure, there are some gaps in the data sets for each monitoring location. The probes and the MA were maintained and calibrated as regularly as practically feasible. The probes, designed specifically for long-term deployment, were recalibrated within 3-6 months through a rotational program whereby an additional probe was 
made available to allow immediate replacement of a probe when it was removed for recalibration in the laboratory. The MA self-calibrated once a day at 12:30 am using a single solution, however due to the relatively harsh nature of the sample water, maintenance requirements for the MA were somewhat intensive and the system would frequently go off-line. Manual recalibration of the MA was also periodically performed to ensure collection of consistently high quality data.

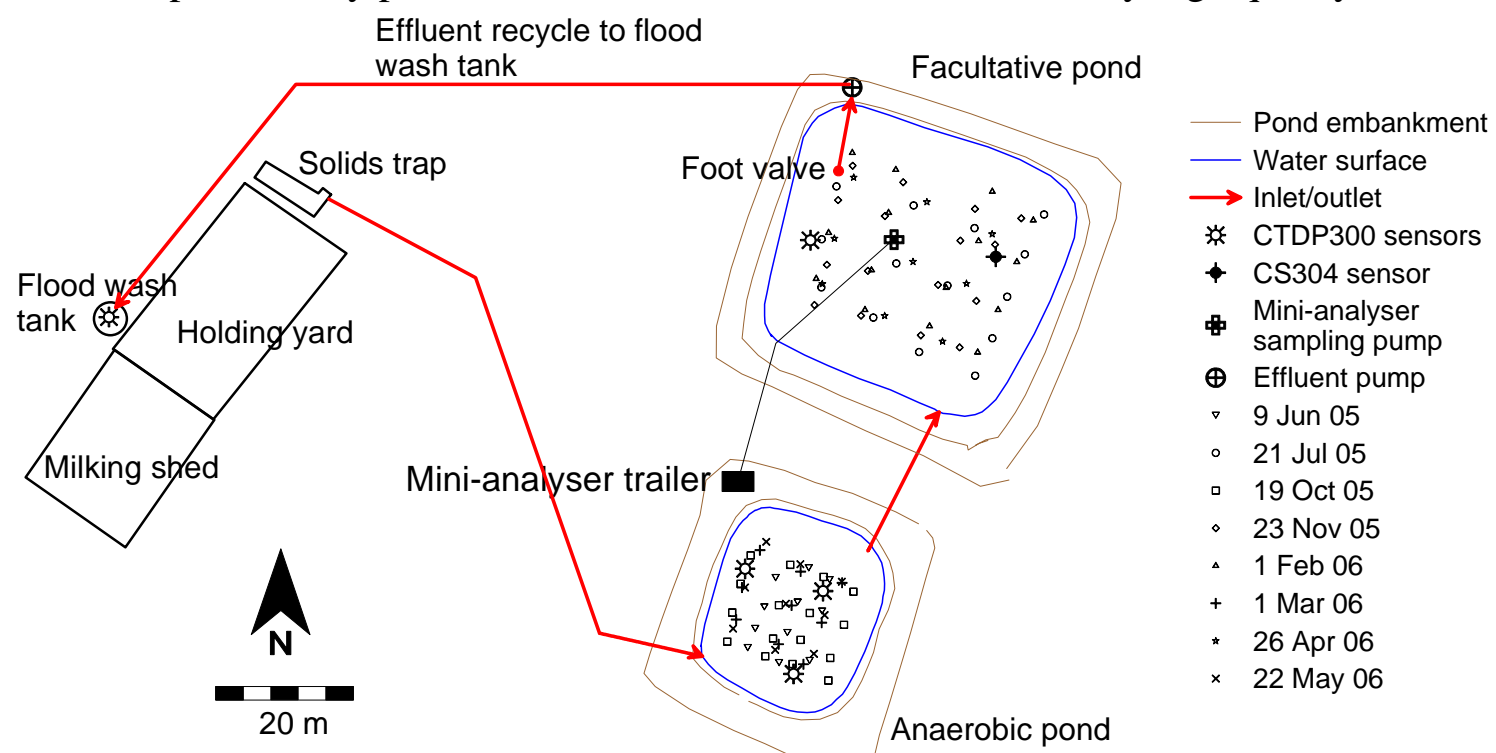

Figure 1 Continuous monitoring probe locations and supernatant profiling points. Profiling points are arranged by date (refer to legend). Note the combined position of the milking shed, holding yard, solids trap and flood wash tank relative to the pond system is not to scale.

\section{Profiling}

In addition to the collection of continuous supernatant data, water column profiling was undertaken to investigate stratification within the two ponds at different times of the year. This involved lowering a hand held multi-parameter probe (YSI 556) into the supernatant in each pond and logging simultaneous measurements of temperature, EC, $\mathrm{pH}, \mathrm{ORP}$ and $\mathrm{DO}$ at set depth increments. Profiling runs were undertaken in June (winter), October (spring), March (late summer) and May (autumn) on the anaerobic pond, and in July (winter), November (spring), February (summer) and April (autumn) on the facultative pond. On each run, at least 9 points in the pond were profiled in an approximate square grid pattern. The profiling was conducted from a small boat which was manoeuvred in straight lines across the ponds with the assistance of a rope fixed to fence posts on opposing embankments. The location of each profiling point was surveyed using a Leica TN400N electronic total station and/or a Trimble Pro XR sub-metre GPS.

\section{RESULTS AND DISCUSSION \\ Long-term continuous monitoring}

The continuous monitoring of temperature in the anaerobic pond reveals a remarkable consistency between the temperature readings taken at three different probe locations (West, Central and Southeast). This is illustrated in Figure 2 in which the 2-day moving average trend lines are fitted to the data from each of the three individual probes. The plots are almost indistinguishable from each other suggesting that temperature can be considered to be uniform across the length and breadth of the pond between 0.5 and $1.0 \mathrm{~m}$ depth. The seasonal nature of in-pond temperature is also clearly visible. There was reasonable consistency in $\mathrm{pH}$ readings between the probes in the anaerobic pond, with levels ranging between 7.0 and 7.4 and changing in the same direction across the pond as shown in Figure 3. These levels match closely the $\mathrm{pH}$ levels of effluent from a similar anaerobic pond measured by Mason (1996). There does appear to be small offset differences between the probe locations, although this could be more as a result of errors in calibration. Figure 4 shows a trend of increasing conductivity levels over time measured by all three probes. Also, the levels are 
significantly higher than levels reported for other anaerobic ponds treating dairy shed waste (Sweeten and Wolfe, 1994; Mason, 1997). There is evidence of sludge encroachment into the upper metre of the water column indicated by sharp drops of up to $1000 \mu \mathrm{S} / \mathrm{cm}$ in the period from early September leading up to pond desludging.

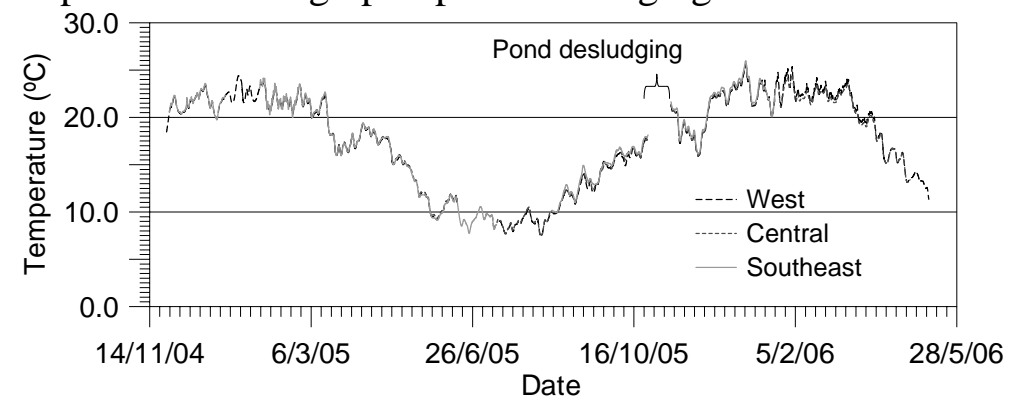

Figure 2 Temporal temperature variation in the anaerobic pond measured at three different locations.

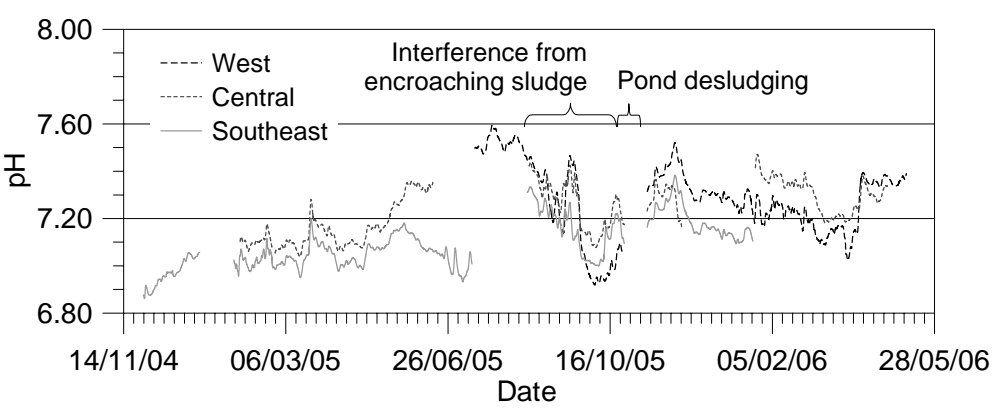

Figure 3 Temporal pH variation in the anaerobic pond measured at three different locations.

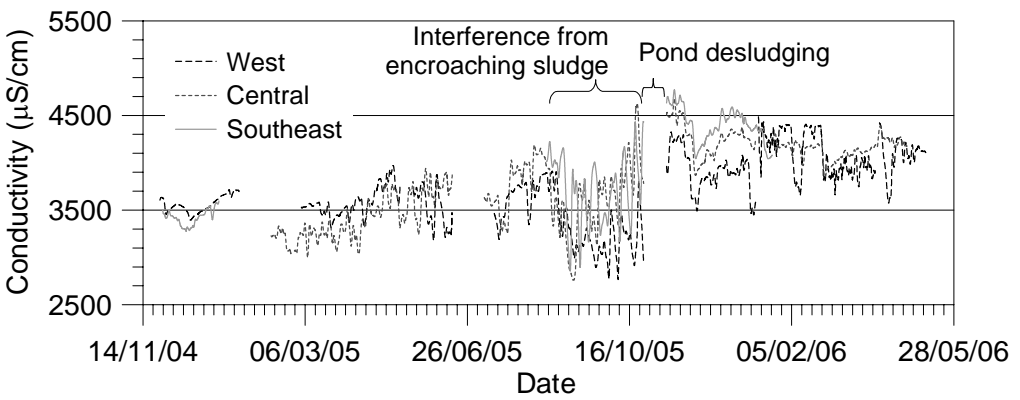

Figure 4 Temporal conductivity variation in the anaerobic pond measured at three different locations.

Temperature readings from the various monitoring points in the facultative pond and effluent holding tank did not show the same degree of consistency displayed by the probes in the anaerobic pond (see Figure 5); although this could be explained by differences in the depths the probes were deployed as evidenced by the results of the profiling described below. Conductivity, however, displayed more consistency between monitoring points. Figure 6 shows the smoothed (2-day moving average) conductivity data from the facultative pond. Note the two sharp drop in conductivity levels - the first in early July as a result of high rainfall (238 mm between 24 June and 13 July) and the second in early November caused by the cessation of inflow from the primary pond due to desludging (mostly dramatically detected by the probes closest to inlet) - were picked up by all probes signifying a uniform response to stimuli across the area of the pond. Also the gradual decline in EC levels in the most recent months is a result of more frequent rainfall ( $247 \mathrm{~mm}$ from the beginning of May to the end of July of 2006). Of significance is the overall steady increase in EC levels similar to that observed in the anaerobic pond, and again levels are higher than reported values from similar dairy shed facultative ponds (Hickey et al., 1989; Sweeten and Wolfe, 1994; Mason, 1996; Sukias et al., 2001). This apparent accumulation of salts is a result of continued recirculation of reclaimed effluent, a phenomenon explored by Atzeni et al. (1995) and Mason and Flowerday (2005) using model simulation. Neither of the ponds have reached the dissolved salts 
levels anticipated in the Mason and Flowerday model despite the system having been in operation for 4 years (2920 reuse cycles), however this could be due to the fact that it is a two-pond system (as opposed to a single pond in the model) and the model not accounting for rainfall and evaporation. Further investigation of salt accumulation is strongly recommended as it is believed to be contributing to the precipitation of struvite crystal which is causing fouling of pumps and fittings in the recirculation system.

Facultative pond $\mathrm{pH}$ data did not display the same consistency between probes as the EC data (see Figure 7); however this was again attributable to problems caused by poor or failing calibrations (pre-2006 data). With improved recalibration efforts from January 2006, the $\mathrm{pH}$ data converges in the latter stages of the monitoring. The combined $\mathrm{pH}$ data with a mean value of 8.03 corresponds well with published data (Hickey et al., 1989; Mason 1996; Sukias et al., 2001). DO readings were the least consistent of the parameters measured in the facultative pond, both on account of spatial and rapid temporal variation of DO levels in the pond, and also in part due to the different sensors used in the probe and the Mini-analyser. Both probes did, however, reveal in Figure 8 a clear pattern of DO reaching supersaturation on clear days in the warmer seasons and remaining close to zero the remainder of the time. DO was measured in the anaerobic pond for the first half of 2005, but as would be expected in an anaerobic pond, DO levels never moved above zero, and thus the CS304 sensor was redeployed elsewhere.

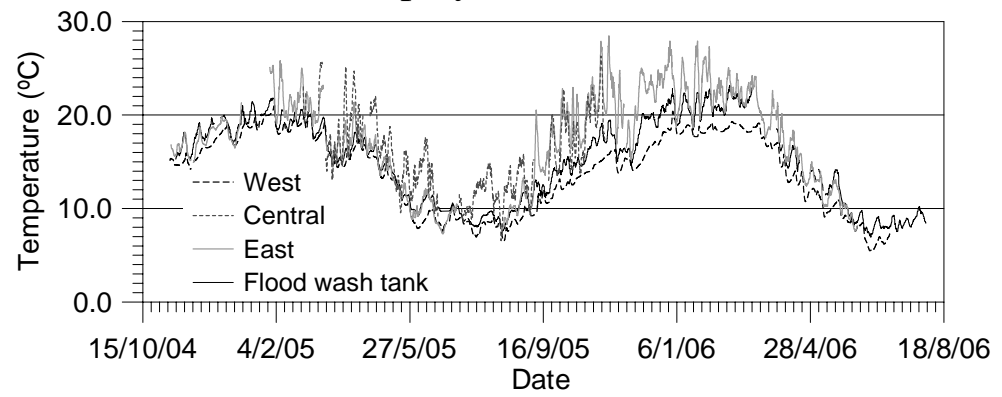

Figure 5 Temporal temperature variation in the facultative pond measured at three different points within the pond and in the flood wash tank containing effluent from the pond for reuse

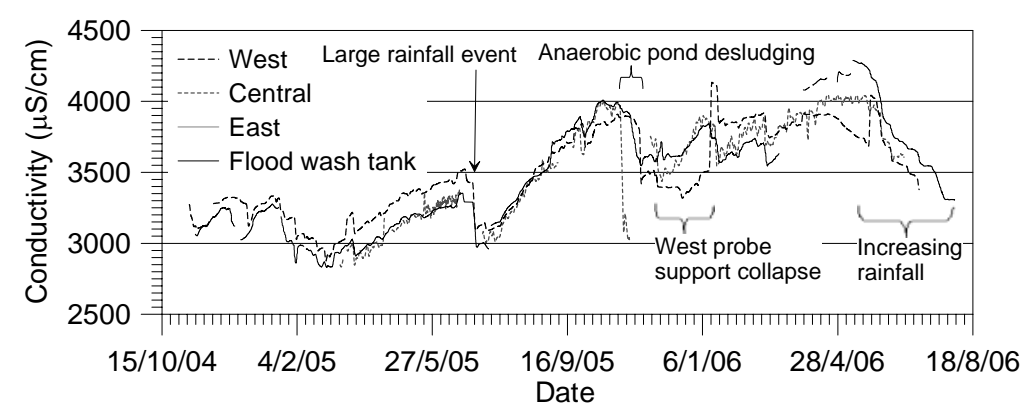

Figure 6 Temporal conductivity variation in the facultative pond measured at three different points within the pond and in the flood wash tank containing effluent from the pond for reuse.

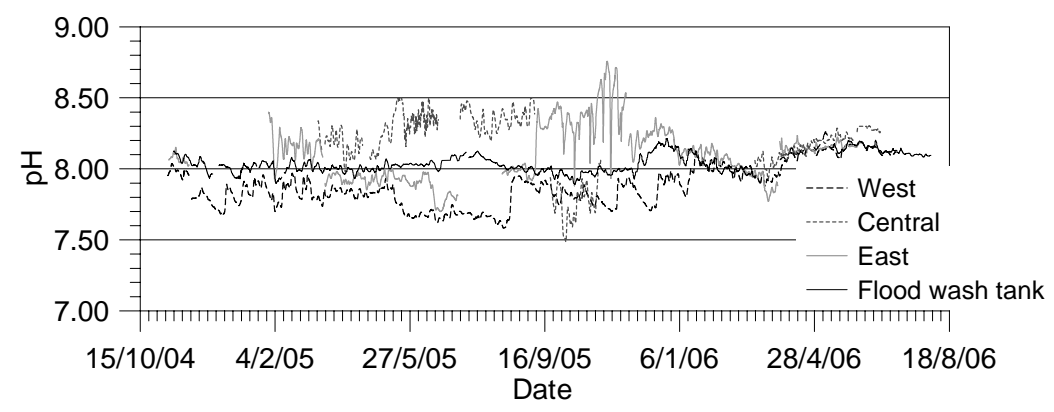

Figure 7 Temporal $\mathrm{pH}$ variation in the facultative pond measured at three different points within the pond and in the flood wash tank containing effluent from the pond for reuse. 


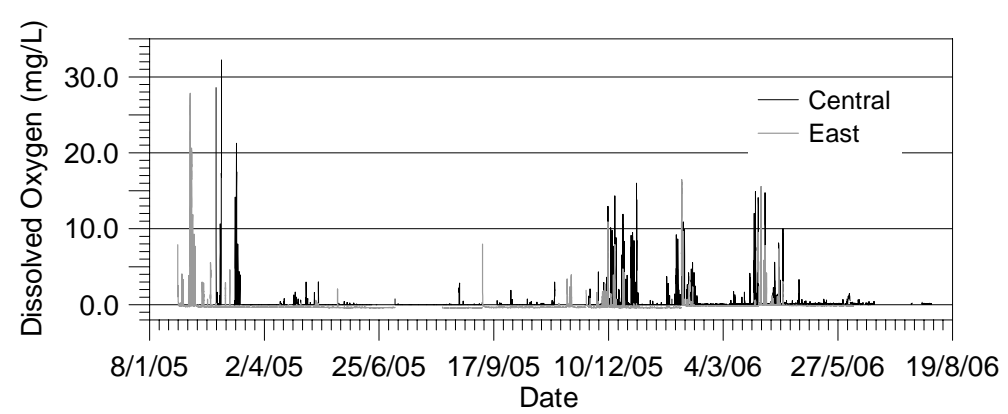

Figure 8 Temporal DO variation in the facultative pond measured at two different locations.

To determine the statistical relationship between the continuous monitoring data from different locations in the ponds, the conductivity data sets from each pond were paired and analysed for covariance and Pearson's correlation coefficient. The data from the flood wash tank probe was not included since the probe was located in the pond itself. The covariance values for all pairings sit between the variances of the individual probe data sets (covariance of an individual data set with itself, eg. west vs west), verifying that conductivity levels in the ponds tend to change in the same direction. The Pearson correlation coefficients for the data pairs tended towards unity (linearity), further demonstrating the coherency of the data gathered from different locations in each pond. These results suggest that we can assume that the ponds tend to respond to the stimulus from influent loading and other external factors such as rainfall and temperature in a uniform manner across their width and breadth. Moreover it could be suggested that the mixing regime in at least the upper $1 \mathrm{~m}$ of the supernatant column of both the ponds is closer to a complete mixed reactor than a plug flow or even partially dispersed reactor. The results of the statistical analyses are presented in Table 1.

Table 1 Descriptive statistics, covariance and correlation analysis for conductivity.

\begin{tabular}{|c|c|c|c|c|c|c|c|c|c|c|}
\hline \multirow{2}{*}{$\begin{array}{l}\text { Probe Location } \\
\text { Anaerobic pond }\end{array}$} & \multirow[t]{2}{*}{ Count } & \multirow{2}{*}{$\begin{array}{l}\text { Mean } \\
\mu \mathrm{S} / \mathrm{cm}\end{array}$} & \multirow{2}{*}{$\begin{array}{c}\text { Standard } \\
\text { deviation, } \mu \mathrm{S} / \mathrm{cm}\end{array}$} & \multirow{2}{*}{$\begin{array}{l}\text { Median } \\
\mu \mathrm{S} / \mathrm{cm}\end{array}$} & \multicolumn{3}{|c|}{ Covariance } & \multicolumn{3}{|c|}{ Correlation coefficient } \\
\hline & & & & & West & Central & Southeast & West & Central & Southeast \\
\hline West & 8558 & 3709 & 246 & 3642 & 60614 & & & 1.00 & & \\
\hline Central & 7465 & 3813 & 440 & 3781 & 91305 & 193221 & & 0.74 & 1.00 & \\
\hline Southeast & 8558 & 3885 & 460 & 3765 & 87663 & 169360 & 211404 & 0.77 & 0.91 & 1.00 \\
\hline Combined & 24581 & 3802 & 399 & 3712 & & & & & & \\
\hline Facultative pond & & & & & West & Central & East & West & Central & East \\
\hline West & 22733 & 3494 & 313 & 3446 & 98264 & & & 1 & & \\
\hline Central & 9528 & 3566 & 353 & 3630 & 91532 & 124274 & & 0.88 & 1 & \\
\hline East & 22733 & 3477 & 381 & 3436 & 97983 & 105472 & 145165 & 0.82 & 0.90 & 1 \\
\hline Combined & 54996 & 3500 & 351 & 3471 & & & & & & \\
\hline
\end{tabular}

\section{Profiling}

Figure 9 presents the temperature, $\mathrm{pH}$ and EC supernatant profiles for the anaerobic and facultative ponds, and the DO and ORP profiles for the facultative pond. Temperature profiles show there is no temperature gradient with depth in the anaerobic pond at any time of year. Sharp decreases in conductivity and $\mathrm{pH}$ in the anaerobic pond were observed to correspond with the height of sludge blanket. The profiles are almost identical in shape to that recorded by Paing et al. (2000) showing that $\mathrm{pH}$ or EC measurements can be reliably used to determine sludge levels in anaerobic ponds. The depth of supernatant above the sludge layer receded significantly between June and October due to rapid sludge accumulation. In the supernatant above the sludge layer, $\mathrm{pH}$ and EC were consistent down the profile, suggesting again extensive mixing throughout the pond. 


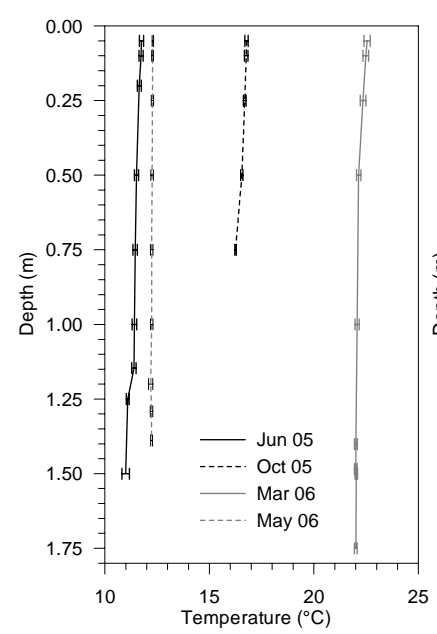

(a)

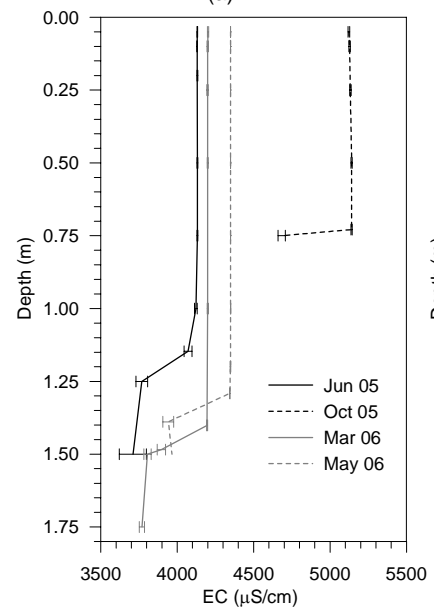

(e)
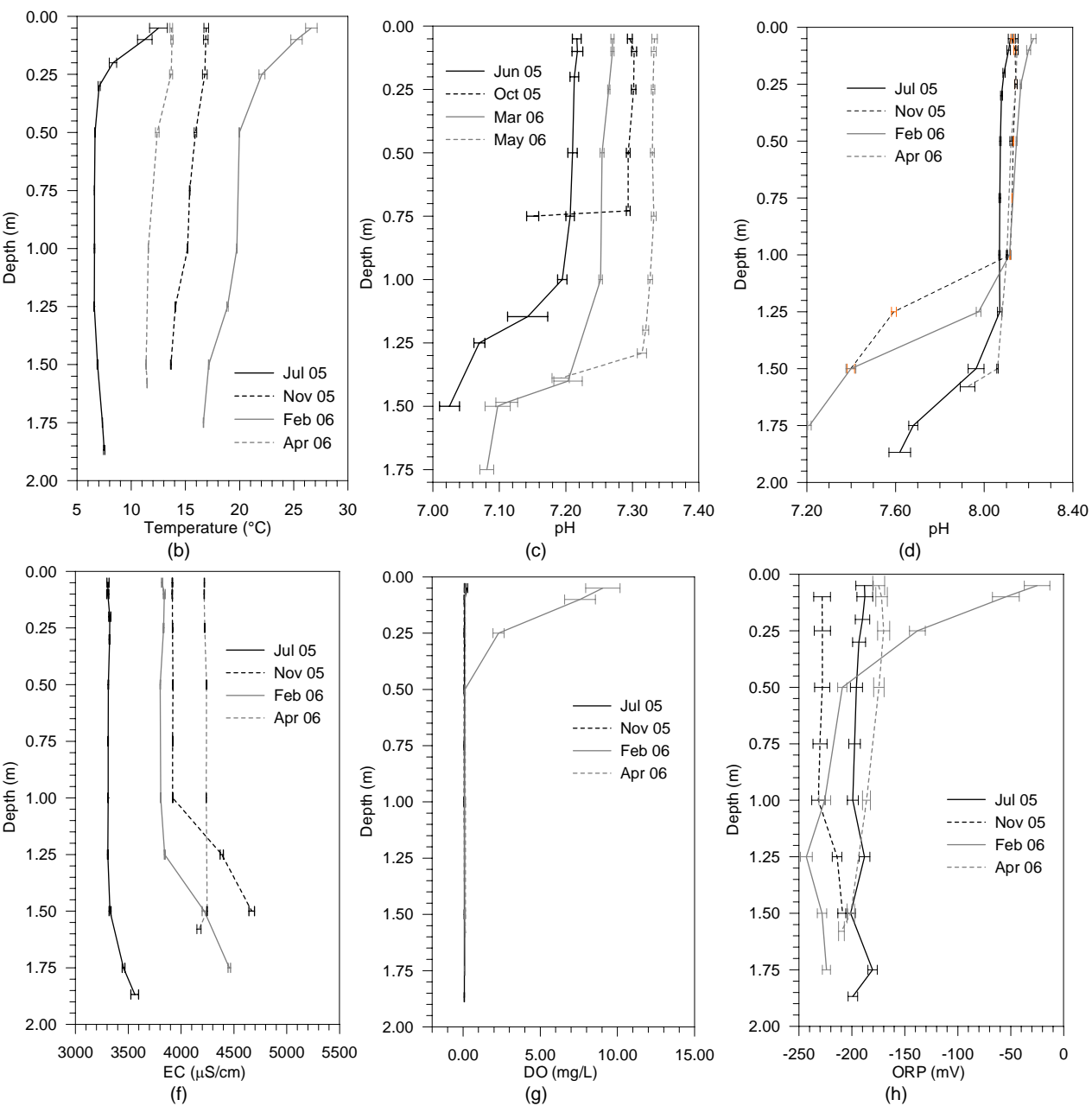

Figure 9 Supernatant physio-chemical parameter profiles measured at different times of the year: (a) Anaerobic pond temperature; (b) Facultative pond temperature; (c) pH in Anaerobic pond; (d) pH in Facultative pond; (e) Conductivity in anaerobic pond; (f) Conductivity in facultative pond; (g) Dissolved oxygen in facultative pond; (h) ORP in facultative pond. Error bars indicate standard error of the mean value calculated from the total number of profiles measured in the run.

Interestingly the same depth consistency was evident in the milder temperature months in the facultative pond, however in the summer and winter months when temperatures reached their respective extremes, a thermocline forms. This is likely due to inadequate mixing between upper and lower layers. The results from the profiling in the facultative pond revealed the presence of two distinct layers within the pond. The upper water column has a consistent conductivity and $\mathrm{pH}$ while below $1 \mathrm{~m}$ the parameters approach levels similar to those encountered in the anaerobic pond (see plots (d) and (f) in Figure 9), except for in April 2006 when there was no gradient to speak of. It would appear that for some periods during the year, thermal stratification prevents complete mixing through the depth of the pond. DO and ORP levels in the facultative pond showed little to no vertical variation in the cooler months but a steep gradient in the summer, again highlighting the dependence of the pond on photosynthetic aeration from algae. Importantly, aeration of the supernatant does not penetrate much beyond $25 \mathrm{~cm}$ depth, which again suggests incomplete mixing through the depth of the pond. Similar DO gradients were observed by Tadesse et al. (2004) in an advanced pond system treating wastewater of comparable strength from a tannery. Of note too are the strong and seemingly permanent reducing conditions (around $-200 \mathrm{mV}$ ) present below the epilimnion.

The profiling experiments verified the uniformity of parameters across the horizontal plane of both ponds identified earlier with little variation evident between profiling points (indicated by the error bars on the profile plots). Conductivity profiling also verified the rising EC trend identified in data 
from the permanently deployed probes, with profiles moving into higher EC ranges with each run, the October profile in the anaerobic pond being the only exception most likely due to the very high sludge level at the time.

\section{Diurnal fluctuations}

Closer inspection of the continuous monitoring data from all three probes in the anaerobic pond revealed that there is no discernibly consistent diurnal variation in $\mathrm{pH}, \mathrm{EC}$ or $\mathrm{DO}$ in the pond at any time of the year. Only wastewater temperature fluctuates in a consistent pattern over the course of the day following normal air temperature swings. The same can be said for the hypolimnion of the facultative pond (observed in the west probe data). In the epilimnion (monitored by the east probe and MA), however, during warmer periods of the year, $\mathrm{DO}, \mathrm{pH}$, ORP and turbidity all fluctuate diurnally in concert with temperature as a direct result of algal photosynthesis (refer to Figure 10 $\mathrm{pH}$ not included). During the colder months the photosynthetic aeration capacity of the algae is not strong enough to overcome the oxygen demand of the wastewater and produce measurable DO levels, but there are still noticeable peaks in $\mathrm{pH}$ and ORP that coincide with temperature variation. These results are in close agreement with the diurnal variation observations reported by Sukias et al. (2001), Sukias et al. (2003) and Tadesse et al. (2004). This behaviour would suggest improved reduction of soluble organic matter during warmer months; however, this simultaneous elevation of turbidity due to algal growth may counteract this improvement.

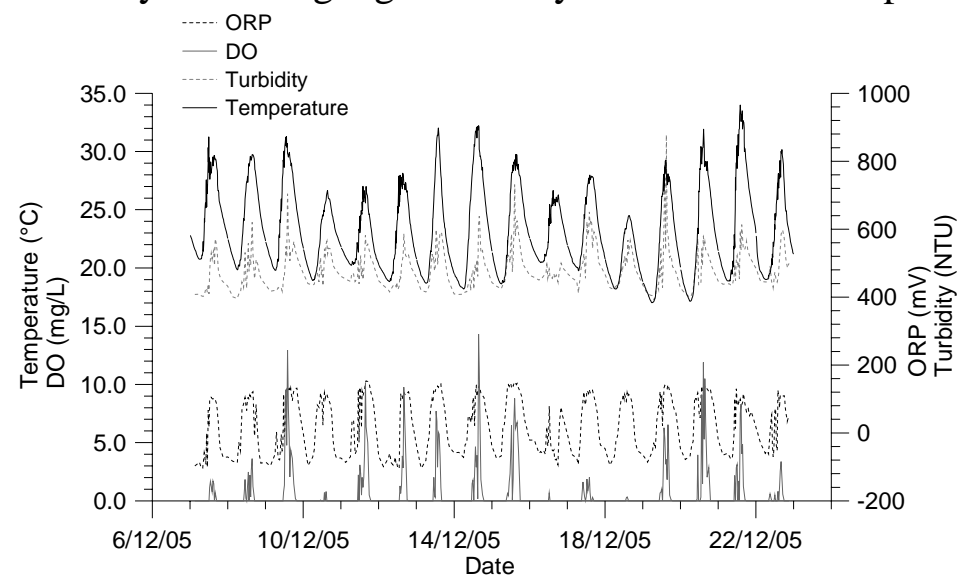

Figure 10 Summer diurnal fluctuations of temperature, dissolved oxygen, oxidation reduction potential and turbidity in the epilimnion of the facultative pond during.

\section{CONCLUSIONS}

The results of continuous monitoring and water column profiling of the anaerobic and facultative stabilisation ponds show that both ponds display homogeneity of supernatant quality across their surface areas and spatial uniformity in their response to various stimuli such as rainfall and changed loading patterns. Mixing within the upper water column ponds thus appears to be closer to a completely-mixed regime than plug flow. Lack of gradient in the supernatant profiles of the anaerobic pond suggests that the entire pond can be considered completely mixed. Conversely, the facultative pond exhibited significant stratification, displaying consistency only in the upper metre of the supernatant. Hence it is recommended that the assumption of complete mixing typically used in the design of dairy shed facultative ponds be reviewed. Significant seasonal diurnal fluctuations in the epilimnion of the facultative pond revealed in the continuous monitoring data would improve aerobic treatment but associated high algae levels potentially negate the effect. Continuous monitoring revealed a long-term trend of dissolved salt accumulation arising due to effluent reuse a problem that requires further research as related operational problems such as pump fouling from crystal deposits begin to surface. This study has developed a comprehensive depiction of the dynamics of the physio-chemical parameters that underpin dairy shed waste stabilisation pond functionality. While the primary aim of this study was to monitor supernatant conditions and 
variability, it is envisioned that this collection of high-resolution data will also provide a strong platform for dynamic modelling of effluent mineral components.

\section{ACKNOWLEDGMENTS}

The authors would like to acknowledge the financial support given to this project by the Sydney Catchment Authority and the NSW Department of Infrastructure, Planning and Natural Resources. Also, this study has been kindly facilitated and encouraged by the farm owners, the Maloney family.

\section{REFERENCES}

Aneja, V.P., Bunton, B., Walker, J.T., and Malik, B.P (2001). Measurement and analysis of atmospheric ammonia emissions from anaerobic lagoons. Atmospheric Environment, 35, 1949-1958.

Atzeni, M.G., McGahan, E.J. and Casey, K.D. (1995). Modeling sustainable piggery effluent disposal. In: Queensland Pig Research and Development Seminar, Proceedings of the First Research and Development Seminar of the Queensland Pig Consultancy Group, 8 September 1995, University of Queensland.

Bolan, N.S., Wong, L. and Adriano, D.C. (2004). Nutrient removal from farm effluents. Bioresource Technology, 94, 251-260.

Hickey, C.W., J.M. Quinn, and R.J. Davies-Colley (1989). Effluent characteristics of dairy shed oxidation ponds and their potential impact on rivers. New Zealand Journal of Marine and Freshwater Research, 23, 569-584.

Kayombo, S., Mbwette, T.S.A., Mayo, A.W., Katima, J.H.Y. and Jørgensen, S.E. (2002). Diurnal cycles of variation of physical-chemical parameters in waste stabilization ponds. Ecological Engineering, 18, 287-291.

Mason, I.G. (1996). Performance of a facultative waste stabilization pond treating dairy shed wastewater. Transactions of the ASAE, 40(1), 211-218.

Mason, I.G. and FLowerday, M.V. (2005). Simulation of inert component accumulation during the recycling of farm dairy wastewater. Biosystems Engineering, 92(2), 265-273.

Sukias, J.P.S., Tanner, C.C., Davies-Colley, R.J., Nagels, J.W. and Wolters, R. (2001). Algal abundance, organic matter, and physico-chemical characteristics of dairy farm facultative ponds: implications for treatment performance. New Zealand Journal of Agricultural Research, 44, 279-296.

Sukias J.P.S., Craggs R.J., Tanner C.C., Davies-Colley, R.J. and Nagels, J.W. (2003). Combined photosynthesis and mechanical aeration for nitrification in dairy waste stabilisation ponds. Water Science and Technology, 48(2), 137-144.

Sund, J.L., Evenson, C.J., Strevett, K.A., Nairn, R.W., Athay, D. and Trawinski, E. (2001). Nutrient conversions by photosynthetic bacteria in a concentrated animal feeding operation lagoon system. Journal of Environmental Quality, 30, 648-655.

Sweeten, J.M. and Wolfe, M.L. (1994). Manure and wastewater management systems for open lot dairy operations. Transactions of the ASAE, 37(4), 1145-1154.

Tadessa, I., Greenb, F.B. and Puhakka, J.A. (2004). Seasonal and diurnal variations of temperature, dissolved oxygen in advanced integrated wastewater systems treating tannery effluent. Water Research, 38, 645-654. 